\title{
THE INFLUENCE OF CLIMATE SCIENCE ON WATER MANAGEMENT IN WESTERN AUSTRALIA Lessons for Climate Scientists
}

\author{
by Scott Power, Brian Sadler, and Neville Nicholls
}

\section{Unprecedented drying in Western Australia led to a partnership between researchers and water managers.}

T he Water Corporation of Western Australia (WA) is the major supplier of water to residents of Perth. Approximately $70 \%$ of the water supplied is used domestically, and approximately 50\% of this is used in household gardens (Meinck and Leathersich 2003). Demand has been close to, and on occasions exceeded, supply over the past 30 years as the city has grown and as a long dry spell has unfolded. Water flow into Perth's dams has dropped by about $50 \%$ since the mid-1970s from the 1911-74 long-term average. This unprecedented decline has severely challenged water managers.

AFFILIATIONS: POWER AND NiCHOLLS-Bureau of Meteorology Research Centre, Melbourne, Australia; SADLER-The Indian Ocean Climate Initiative, Perth, Australia

CORRESPONDING AUTHOR: Dr. Scott B. Power, Bureau of Meteorology Research Centre, GPO Box 1289K, Melbourne, VIC 3001, Australia

E-mail: s.power@bom.gov.au

DOI:10.1175/BAMS-86-6-839

In final form 4 January 2005

C)2005 American Meteorological Society
The decline has been accompanied by an increased understanding of climate science. Our aim here is to describe the influence that climate science has had on decision making by the water managers in WA. We will pay particular attention to a research partnership called the Indian Ocean Climate Initiative (IOCI) that was started largely in response to the drying. We will outline the extent to which IOCI has influenced decision making in WA, what decision makers think about climate science information, and what climate research scientists have learned about helping decision makers in the wider community.

BACKGROUND. Perth $\left(32^{\circ} \mathrm{S}, 116^{\circ} \mathrm{E}\right)$ is the capital of the state of WA. It is located on a narrow coastal plain in the southwest of WA. Perth has a population of 1.4 million people. Current and projected population growth rates are approximately $1.8 \% \mathrm{yr}^{-1}$.

Rainfall collects in river catchments on slopes near the coast and in shallow aquifers on the coastal plain. Most of the rain falls in the cooler months (May-October). Water from both river catchments and the subsurface is heavily utilized by Perth's residents. 
THE CONTEXT OF DECISION MAKING. The Department of Environment is responsible for managing water in the state. It grants the Water Corporation a license to use state water. The Water Corporation has operated since 1996 as a state-owned commercial entity, with profits [e.g., \$240 million in U.S. dollars-after tax last financial year (Water Corporation 2003)] going to the government. Users have had to pay for water since the mid-to-late 1970s (Hughes 2002).

While commercial viability is a statutory requirement for the corporation, the corporation has a charter to be socially responsible, environmentally sound, and technologically robust (Water Corporation 2003). These goals are met through both regulation and a prevailing culture in the organization that strongly supports this more holistic philosophy. The regulations require transparency in decision making, and they tie environmental and conservation goals to approval for requests to expand water storage.

A key feature of the broader environment in which the water managers make decisions is that domestic gardens are very popular in Perth, as they are in the rest of Australia. Residents will accept limited restrictions on water use, but they will not tolerate a complete ban on water use in private gardens. The last total ban on garden sprinklers occurred in 1978-79. Complete bans create strong debate in the wider community. This situation has become more intense with the emergence of a vibrant gardening industry in Perth worth about $\$ 800$ million per year (Hughes 2002). Total bans have been estimated to cause losses of $\$ 300$ million and 4000 jobs. In recognition of this the government has a policy that additional sources of water will be accessed to "ensure that the likelihood of a total sprinkler ban is small" (WA Government 2003). Water managers are required to operate within this policy.

\section{DECISION MAKING SINCE THE MID-}

I980S. By the mid-1980s water managers were concerned about the decline in rainfall over the preceding decade. The dry conditions were viewed as an unfortunate run of dry years that was very likely a natural occurrence, but which nevertheless required adjustments to water yield expectations and water system design. At the same time awareness of global warming as an issue was growing worldwide. Following the Villach climate conference in 1985, Australia's largest scientific research agency [The Commonwealth Scientific and Industrial Research Organization (CSIRO)] held a national conference called Greenhouse 87 (Pearman 1988). The scenarios at the time included a $20 \%$ decline in rainfall by 2040 over southern Australia that extended to the southwest. This decline was linked to storm tracks shifting south away from Australia. Water managers estimated that this scenario would lead to a $40 \%$ decline in river flow (Sadler et al. 1988). The paper proposed that an appropriate response to a projected decline of this kind would include a gradual "derating" of the expected supply from the existing water sources. Derating is the term water managers use to describe a downgrading of the expected long-term mean inflow expected from the system. This meant that water sources had to be developed more quickly than previously planned-at significant additional cost-and efforts to conserve water had to be stepped up. K. Bradley (2003, personal communication) and Meinck and Leathersich (2003) provide details on major programs promoting conservation.

A derating of $13 \%$ was subsequently imposed (Sadler 2003). Some derating would have occurred in the absence of new information from climate science around that time, because of the drying. However, water managers believe that the magnitude of the derating would not have been as large without the climate science information. The climate change information certainly gave water managers additional evidence to consider and some peace of mind in making these difficult decisions. In recognition of the uncertainties involved, the incremental strategy adopted by water managers meant that the derating would be reviewed from time to time, based on additional experience and advances in climate science. Drying due to global warming was clearly identified as a risk for the region that needed to be considered in subsequent planning: "The potential regional magnitude of the climate change problem, on the one hand, and the uncertainty which surrounds predictions, on the other hand, present a classic dilemma for decision-makers. Development of a well balanced response may take decades and will require appropriate information for decision-makers" (Sadler et al. 1988).

This position was not universally accepted within the broader community. Some believed that climate change projections were so uncertain that the information should not be factored in at all. The position adopted by the water managers was therefore controversial in some quarters.

By the early 1990s the water managers were deeply worried. Rainfall and inflow remained low. In 1996 the managers instigated a national climate variability workshop (Ruprecht et al. 1996) and invited water managers, representatives of state government agencies, and climate scientists from across Australia and 
from overseas. The meeting counseled caution on blaming global warming for the drying, while at the same time reconfirming that this was a possibility that needed to be considered. While the workshop endorsed the incremental strategy applied since 1995, they reasoned that the abrupt onset of the dry spell and the duration of the dry spell were unusual enough to be viewed more as a "regime shift" than a downward trend. The workshop recommended a further review of planning assumptions. An additional derating was subsequently made in 1998 under the assumption that rainfall in the region had changed and was now better characterized by rainfall levels over the previous 20 years than over the entire record. This single derating cost $\$ 400$ million, due to, for example, bringing forward plans to expand the storage network, and it led to additional costs in subsequent years. It presented major challenges for water managers who had to bring on new water sources.

The workshop in 1996 also identified that a number of state agencies wanted more research into climate variability and climate change dealing with issues of concern to people in southwest WA. Further research was recommended as one strand of a much broader risk management strategy. In recognition of the potential benefits of further research, the state government in 1998 established the IOCI ( $w w w$.ioci. org.au/). IOCI is a partnership between state agencies representing various sectors affected by climate variability, and the national research institutions of CSIRO and the Bureau of Meteorology Research Centre (BMRC). IOCI is led by the IOCI panel, which comprises representatives of the partner agencies (including water managers) and scientists of the partner research institutions. The panel sets out a strategic program of research in support of major decision issues and facilitates efficient communication between decision makers and climate scientists. It assists with increasing the understanding of resource management needs by climate scientists and in clarifying science issues, for example, what can and cannot be delivered in a sound scientific manner. The panel also acts as a focal point and leader for climate issues within the broader community.

IOCI's first stage of research ran from January 1998 to December 2002. This research characterized the change in rainfall and confirmed it as a regime shift-unusual, but not inexplicable, in terms of natural multidecadal variability. The rainfall changes were shown to be associated with large-scale changes in the atmospheric circulation, and a simultaneous increase in regional temperatures was noted. IOCI also concluded that "Most likely, both natural variability and the enhanced greenhouse effect have contributed to the rainfall decrease" and that "the 20th Century warming in the southwest is largely the result of the enhanced greenhouse effect" (Indian Ocean Climate Initiative 2002).

IOCI drew upon results from other sources. The two most important were the Intergovernmental Panel on Climate Change (IPCC) - for example, that "there is now new and stronger evidence that most of the warming observed over the last 50 years is attributable to human influence" (Houghton et al. 2001) —and CSIRO's updated climate projections for Australia (Australian Greenhouse Office 2002). The scenarios again suggested that global warming will tend to reduce rainfall in the southwest over coming decades.

The water managers are aware of the uncertainty associated with climate change scenarios and the fact that large differences between the projections and observed changes exist-for example, in timing and magnitude. This collection of work from IOCI, IPCC, and CSIRO has nevertheless entrenched drying by global warming as a risk that needs to be considered in their planning.

\section{DID CLIMATE SCIENCE INFLUENCE OR HELP WATER MANAGERS? While most de-} cisions were driven by the observed drying, water managers have no doubt that climate science and IOCI have influenced their decision making and have been of assistance to them. Some of the reasons and evidence for this are summarized below:

i) Water managers believe that climate science influenced the magnitude of the derating they imposed.

ii) Water managers want the best available advice. They need to be seen taking independent advice, to reassure the public that restrictions were necessary because rainfall and inflow declines were unusually large and unusually abrupt, and not because of poor management.

iii) The products and advice that IOCI provided became available toward the end of an exceptionally dry two-year period in 2001-02. This drought further increased interest in water management and climate science issues, and the IOCI products and information were in very high public demand. Ready access to the information was very useful to the water managers in helping them inform the wider community.

iv) Water managers have a strong sociopolitical and financial need to avoid severe restrictions. This sensitivity made it imperative for the WA water 
managers to consider climate science in their planning. Scrutiny of the planning process can become intense after restrictions are imposed. At these times it would probably be unacceptable to many if a known risk to supply was ignored in earlier planning even if the evidence at the time was regarded as inconclusive.

v) The involvement of water managers in IOCI, and an increased awareness and understanding of climate issues generally has had a substantial impact on the culture of the Water Corporation. Corporation staff became more familiar with climate issues. Both IOCI and IPCC results are routinely used in the public addresses made by staff and by regulatory agencies.

vi) One important function of IOCI has been its ability to "localize" the information for regional consumption: "Local information is far more interesting to residents of WA and so it brings them to meetings that would otherwise not draw them. It brings climate-related issues to the pub bar and the breakfast table at more than the 'strange weather we're having' level" (R. McKellar, Conservation and Land Management, WA Government 2004, personal communication).

vii) The WA state government has been strong in its praise for IOCI and has expressed the view that IOCI has improved decision making. In fact the government has recently announced that a second five-year program-IOCI Stage2-will be funded (e.g., WA Government 2003).

viii) Decision makers outside WA also regard IOCI as an effective way in which to focus attention on regional issues involving climate research. The IOCI model is now being proposed on a larger scale for the Murray Darling Basin in eastern Australia.

\section{WATER MANAGER'S PERSPECTIVES ON} CLIMATE SCIENCE. From a water manager's perspective their support for and involvement in IOCI represents one strand of a broader risk management approach dealing with the possibility of reduced inflows. They have not deferred important decision making on the presumption that climate science will eventually bring certainty. Indeed water managers recognize that this might never occur. They do not make radical changes on the basis of uncertain information, but the information has been used in their planning. In recognition of the uncertainty, they continually review their plans so that they can be revised in light of additional experience gained and as advances are made in climate science. Water managers also recognize the potential for advances to offer greater assistance to their decision making in the future.

Climate science has presented water managers with a relatively new risk among many other risks: "In the end it's all about risk management, the risks of climate 'forecasts' in terms of the credibility of the science and the experts, the risk of 'wasted' investment and the political risks of being seen-in hindsight of course- of not doing enough to secure water supplies soon enough" (R. Stokes, Water Corporation, 2004, personal communication).

\section{LESSONS FOR CLIMATE RESEARCH} SCIENTISTS. It is clear that communication with the water managers has been crucial in underpinning IOCI success. IOCI has provided a framework to explain jargon and to promote realistic expectations, for example, to explain why there are fundamental limits to predictability and that research will not necessarily reduce perceived uncertainty, but can help to clarify levels of uncertainty. Interaction with the water managers led to a shift in research priorities and policy for some of the scientists involved. This can, however, take a long time and requires sustained effort over an extended period.

Scientists became more aware of the fact that water managers prefer certainty but do not always require it. Water managers are well practiced in making use of uncertain information in their planning. Sometimes, however, the climate information provided does not fit in with the water management decision-making processes. It might be at the wrong spatial or temporal scale, it might be too uncertain, or it might not have immediate or obvious implications for their decisions (e.g., Power et al. 2001). Climate science generally will not dictate water policy. There are usually many other issues to consider as well. However, continuing to improve the reliability and relevance of climate information has the potential to build opportunities for using climate science in water management.

Water managers do not just want predictions [for case studies in other contexts for which this is true, see Sarewitz et al. (2000)] or technical information about the scientist's narrow area of specialization within climate science. This sort of information on its own is unlikely to have much impact on decision making because it typically does not clearly address current policy or planning problems. Instead water managers want explanations, clarification of issues and uncertainties, perspective, and balance. They therefore value professional links with respected scientists that foster trust and credibility. 
The importance of effective communication (including consultation) should not be underestimated. In fact, even after all of the effort put in to communication between IOCI and water managers (with others with an interest in WA water management) over many years, and the design of management structures and processes within IOCI to improve communication, communication remains an ongoing challenge.

Finally, it is worth keeping in mind that not all research requires a close and ongoing liaison with end users. Often research issues of fundamental or technical importance to a particular field are not seen as a high priority for any major user, for example, because the issues do not directly affect the user's current problems or because the user does not think it is their responsibility to fund the research. IOCI, for example, would not fund the development of climate models, yet they are keen to see climate models develop and see potential benefits to WA in further development. We have also seen time and time again throughout history that basic research conducted in one generation can lead to unexpected, major, useful products or services years or even generations later. We also need to recognize that humans are a curious lot-we value advances in understanding for its own sake.

FINAL COMMENTS. In this paper we have discussed how climate research has been used to assist water managers in Western Australia. We have discussed some of the processes that have led to an increase in the influence of climate science on decision making and some of the factors that limit its influence. In making our assessment we have drawn upon Water Corporation and state government publications and conference papers, discussions with a small number of senior managers currently working in the Water Corporation, and our own collective experience in water management, communicating information from climate science to the wider community, and our participation in IOCI.

We have seen that developing and adapting information to better meet the needs of decision makers can be a fascinating, challenging, and rewarding exercise. We have also seen that disentangling and quantifying the impact of climate research on decision making is not as straightforward as it might first seem.

It is important to realize that some of the conclusions we have drawn need not be relevant or correct in other contexts. We restricted our attention to one set of decision makers, in one region, in a country with a developed economy and a modern democracy, to a 15 -year period. We have concentrated on the use of climate science that emerged over that period. The information is complex, evolving, and by no means certain. So we should not expect our conclusions to apply universally. In some other contexts, scientists routinely provide scientific information to the wider community that is easily factored into decision making. In some contexts it is critical for the scientists to remain strictly independent from the agency seeking the advice (e.g., a company or official seeking advice on the environmental impact of waste disposal at a particular site), in which case an IOCI-like structure might be inappropriate.

ACKNOWLEDGEMENTS. We wish to thank Bob Stokes and Colin Terry from the WA Water Corporation for interesting and informative discussions related to this study. Thanks also to Bob, Colin, John Bally, Mike Coughlan, Neil Plummer, and Charlie Zammit for helpful comments on earlier drafts.

\section{REFERENCES}

Australian Greenhouse Office, 2002: Living with climate change: An overview of potential climate change impacts on Australia. Commonwealth of Australia, 36 pp.

Government of Western Australia, 2003: Securing our Water Future: A State Water Strategy for Western Australia. Government of Western Australia ISBN 0730702103,8 pp.

Houghton, J. T., Y. Ding, D. J. Griggs, M. Noguer, P. J. van der Linden, and D. Xiaosu, Eds., 2001: Climate Change 2001: The Scientific Basis: Contributions of WGI to the Third Assessment Report of the Intergovernmental Panel on Climate Change (IPCC). Cambridge University Press, $881 \mathrm{pp}$.

Hughes, G. J., 2002: Meeting the challenge of climate variability in a major water supply system. Enviro2002 Convention and Exhibition, Executive Summaries, Waste Management Association of Australia, $512 \mathrm{pp}$.

Indian Ocean Climate Initiative, 2002: Climate variability and change in south west Western Australia. IOCI, Perth, Australia, 34 pp.

Meinck, G., and M. Leathersich, 2003: Demand management: Western Australia's experience. Paper, Ozwater2003 Convention, Perth, Australia, Australian Water Association, CD-Rom, oz331.

Power, S., W. Wright, and P. Della-Marta, Eds., 2001: CliManage2000, A Conference on Managing Australian Climate Variability, $133 \mathrm{pp}$.

Ruprecht, J. K., B. C. Bates, and R. A. Stokes, Eds., 1996; Climate Variability and Water Resources Workshop. 
Water and Rivers Commission, Water Resources Tech. Rep. Series WRT5.

Sadler, B., 2003: Informed adaptation to a changed climate state. Is south-western Australia a national canary? Living with Climate Change. A National Conference on Climate Change Impacts and Adaptation, Australian Academy of Science, Canberra, 207-217.
G. W. Mauger, and R. A. Stokes, 1988: The water resource implications of a drying climate in southwestern Australia. Greenhouse: Planning for Climate Change, G. I. Pearman, Ed., CSIRO, 296-301.

Sarewitz, D., R. A. Pielke Jr., and R. Byerly Jr., Eds., 2000: Prediction: Science, Decision Making and the Future of Nature. Island Press, 405 pp.

Water Corporation, 2003: Flowing forward. Water Corporation Annual Rep. 2003, 65 pp.

\section{The LIFE CyCles OF}

\section{EXTRATROPICAL CyCLONES}

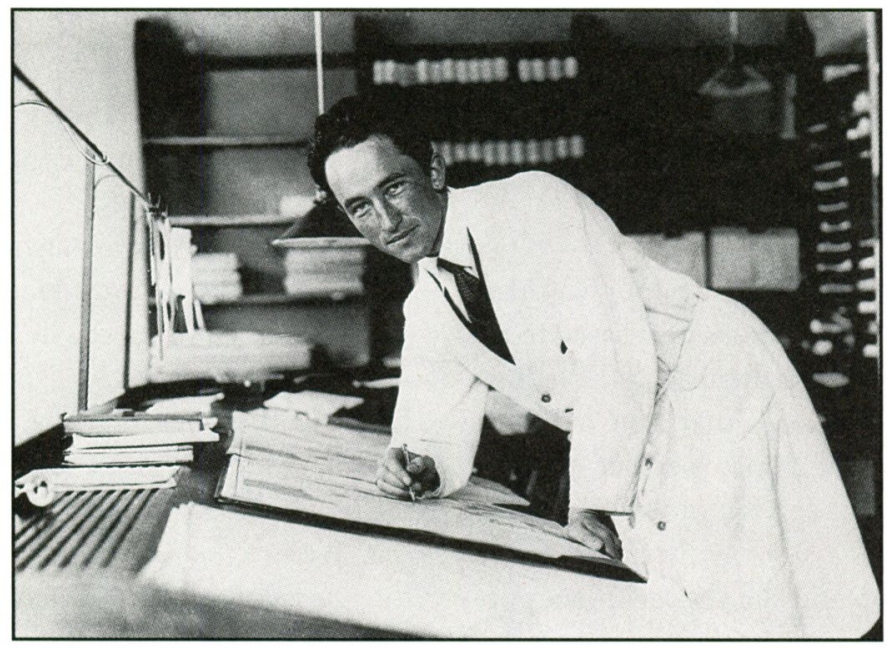

Edited by Melvyn A. Shapiro and Sigbjørn Grønås

Containing expanded versions of the invited papers presented at the International Symposium on the Life Cycles of Extratropical Cyclones, held in Bergen, Norway, 27 June-1 July 1994, this monograph will be of interest to historians of meteorology, researchers, and forecasters. The symposium coincided with the 75th anniversary of the introduction of Jack Bjerknes's frontal-cyclone model presented in his seminal article, "On the Structure of Moving Cyclones." The monograph's content ranges from a historical overview of extratropical cyclone research and forecasting from the early eighteenth century into the mid-twentieth century, to a presentations and reviews of contemporary research on the theory, observations, analysis, diagnosis, and prediction of extratropical cyclones. The material is appropriate for teaching courses in advanced undergraduate and graduate meteorology.

The Life Cycles of Extratropical Cyclones is available for $\mathbf{\$ 7 0 ~ l i s t / \$ 5 0 ~ m e m b e r s . ~ P r i c e s ~ i n c l u d e ~ s h i p p i n g ~ a n d ~}$ handling. Please send prepaid orders to Order Department, American Meteorological Society, 45 Beacon St., Boston, MA 02108-3693 or call (617) 227-2425. Visa, MasterCard, or American Express accepted. 